\title{
Understanding Spiritual Awareness in Terms of Anomalous Information Access
}

\author{
David Rousseau*
}

Department of Theology and Religious Studies, University of Wales, Lampeter, United Kingdom \& Centre for Fundamental and Anomalies Research (C-FAR), Surrey, United Kingdom

\begin{abstract}
In this paper I identify a link between the problem of explaining anomalous access to information ('psi' or 'psychic ability') and the problem of giving an account of the nature of consciousness ('the mind-body problem'). I argue that progress with understanding psi requires selecting a suitable ontological model for dealing with the mind-body problem. I review alternatives and argue, on philosophical and empirical grounds, for the viability and suitability of a model I call Naturalistic Structural Dualism, in which minds are spatially extended substances, as a working hypothesis for further analysis. I conclude that in such a dualistic model psychic ability is best conceptualised as mediated by sensori-motor channels of the mind. I predict, from this, the existence of further sensory channels that engage with purely mental aspects of reality. I show that there is empirical support for this theoretical proposal, and argue that this sensory capacity, which I name axionesis, underpins both ordinary perceptiveness and our capacity for deep spiritual experiences. The outcome is an expansion of the concept of psi to reference two distinct groups of sensori-motor channels of the mind, one group relating to the classical concept of psychic ability (and reflecting the mind's direct engagement with physical aspects of reality) and one group relating to the classical concept of spirituality (and reflecting the mind's direct engagement with mental aspects of reality). By establishing a relationship between spiritual perception and sensory channels of the mind, a framework is created that enables the study of spirituality in terms of information theory.
\end{abstract}

Keywords: Anomalous information, psychic ability, psi, mind-body problem, ontology, Non-Cartesian Dualism, axionesis, spiritual awareness, spirituality, Naturalistic Structural Dualism, NSD.

\section{INTRODUCTION}

Throughout history there have been people who claimed to have special abilities that give them access to information that is inaccessible to ordinary people. Such people have generally been called 'psychic', and their special faculties have been given various names based on the kinds of information they claim to have access to. Examples are remote viewing (the ability to see distant or hidden things, also known as clairvoyance), precognition (knowing what is going to happen), telepathy (knowing what someone else is thinking or feeling), and intuition (knowing the right thing to do in an uncertain situation). On rare occasions ordinary people have extraordinary experiences in which they momentarily have access to such veridical information (see [1] for an analysis of more than 17,000 such cases published in Gurney et al. [2]. Ordinary people can also have powerful experiences like this when under the influence of certain drugs (David Luke has recently provided a comprehensive up-to-date review of research in this area [3]), and sometimes develop such abilities after traumatic incidents, especially those involving head injury [4].

Many spiritual disciplines claim that such abilities emerge as a side-effect of spiritual training (e.g. the siddhis

"Address correspondence to this author at the C-FAR, 30 Leigh Close, Addlestone, Surrey, KT15 1EL, United Kingdom; Tel: +44 1932848312;

E-mail: david@c-far.org described in the Yoga Sutras of Patanjali [5] and the charismatic 'gifts of the Holy Spirit' described in the Bible (1 Cor. 12)). William James, in his classic work The Varieties of Religious Experience described one of the four core characteristics of mystical states as achieved through spiritual practice by its "noetic quality", a "state of knowledge... and insight into depths of truth unplumbed by the discursive intellect" [6]. Such mystical states also occur spontaneously, as Paul Marshall discusses in his insightful recent study Mystical Encounters with Nature [7].

Scientists researching such claims have documented many credible instances of anomalous cognition (see [8] for an accessible overview), and have been able to demonstrate the existence of such abilities under controlled conditions in the laboratory (see [9] for an overview and discussion). More recently, researchers have produced evidence that almost everyone has at least some ability of this kind, for instance most people can tell when they are being stared at from a hidden location, and many mothers know when their babies are in need, even when they are not together ([10] reviews a wide range of such phenomena) ${ }^{1}$.

\footnotetext{
1 Although the evidence for the existence of psi phenomena is very strong, the incidence of strong psi effects or dramatic psychic experiences in the general population is very low [11-13]. Surveys do however reveal a high prevalence of minor psychic experiences $[14,15]$. Under test conditions average people typically display very little or no psychic ability, as evidenced by parapsychological experiments using unselected subjects, where the effects are usually very weak or absent altogether [16]. The basis
} 
It is very surprising that these similar experiences occur under such widely varying conditions. We do not understand what these conditions have in common that enables the emergence or manifestation of these abilities, and we have no scientific understanding of how this information access is possible in the first place. However, its emergence under such a wide range of conditions suggests that it reflects a fundamental human capacity, and research into its source and nature may therefore reveal deep insights into the nature of persons.

Jarkko Kari has suggested that this information is obtained in an extra-physical way, and called such knowledge "spiritual information" [19]. Parapsychologists generally refer to it as anomalous cognition, ESP (originally, 'extrasensory perception') or psi (from the first letter of the Greek term psyche) [20].

These faculties are deeply mysterious because there seems to be no mechanism, in terms of how science understands bodily processes, by which people can obtain this information. On the basis that these faculties appear not to be mediated by the bodily senses it is tempting to regard them as faculties of the mind (e.g. Lousia Rhine entitled her classic survey of psychic cases Hidden Channels of the Mind [21]). However, in the current academic environment this is problematic because the mainstream view, in both philosophy and neuroscience, is that all mental phenomena derive in some way from physical phenomena in the brain.

Although the mainstream view is that mental processes supervene on brain processes, there is no explanation in mainstream philosophy or neuroscience of just how this happens. Trying to explain the relationship has long been called the mind-body problem, but in recent times it has come to be called 'the hard problem', because it seems so very intractable in the light of the foundational assumptions of philosophy and science [22]. The most fundamental of these ontological assumptions is the view that everything that actually exists in a concrete way is either a physical thing, or a state of a physical thing, or a side-effect of a physical process. The upshot is a claim that if you know all the physical facts, then (in principle) you know all the facts. This view is known as Physicalism, and there are many forms of it. The majority of mainstream philosophers and scientists think this perspective is on the right track, and hold that although it is presently problematic to explain consciousness from the physical facts, it will in time be possible to do so. Nevertheless, there is some reason to think that the problem goes deeper than a lack of maturity in the science of consciousness studies: all the forms of physicalism have been charged, by significant philosophers, with having fundamental problems.

Eliminative Physicalism is the view that mental events do not really exist at all, and that talk of them represents some kind of folk-psychological conceptual mistake, in the same way that caloric, phlogiston and ether have been shown not to have any actual referent. Views of this kind can be traced

of this variation in ability is of course not presently understood, but it is a subject of current research [e.g. 17]. Research is also ongoing into methods of training or facilitating psi, e.g. [18]. back to Democritus (c.460 - c.370 BCE) ${ }^{2}$. The modern movement derives from Paul Feyerabend [24], and has been heavily influenced by the work of Daniel Dennett $[25,26]$. Significant current defenders of this view are Patricia Churchland, Paul Churchland and Stephen Stitch. Against this view, Frank Jackson argued that when we first experience something like a colour or an aroma we learn something new beyond what we can extrapolate from a technical description of the physical nature of the perceived object and the physical mechanisms of perception [27,28]. This critique is known as 'the knowledge argument' - for a salient modern defense of it, against a modern version of Dennett's position, see Michael Beaton's [29]. John Smythies has pointed out the practical implausibility of eliminativism. Eliminativism amounts to a claim that we behave as if we have experiences but that we do not really have any [26, footnote 3]. As Smythies observes, there are people who are somewhat like that: they do not experience seeing the phenomenal world due to damage to their occipital lobe ('cortical blindness') but nevertheless act on visual information because their eyes work normally ('blindsight'). If eliminativism were true, we would all be like people with cortical blindness and $100 \%$ accurate blindsight, but no-one would claim that such a patient has normal vision [30].

Reductive Physicalisms represent a set of views according to which mental events are real but are not additional goings-on beyond physical goings-on ${ }^{3}$. According to this perspective, sentient beings do have mental properties, but they have them in virtue of their material properties, and all talk of mental phenomena can, in principle, be translated, without residue, into talk of uniquely correlated physical arrangements. The differences between views of this kind are about what manner of physical goings-on are constitutive of mental states. Thomas Nagel, John Heil and Jaegwon Kim have extensively criticised these views (see [33-35] for accessible overviews). Apart from the individual difficulties particular variants face, it is argued that none of these models can say how it is possible, even in principle, that a wholly physical event such a brain state (which by its nature is $o b$ jective), can be equivalent to a mental event such as a thought, given that it subjectively feels a certain way to have a thought ('qualia') ${ }^{4}$, and given that a thought is about something ('intentionality') ${ }^{5}$. In the absence of a principled argument, reductive physicalism amounts to an implausible brute claim that mental events just are physical events described

\footnotetext{
2 "... by convention sweet and by convention bitter, by convention hot, by convention cold, by convention colour; but in reality atoms and the void" (Democritus, fragment DK 6889 transl. Taylor [23]).

${ }^{3}$ The main ones are: Philosophical Behaviourism, Psychological Behaviourism, Type Identity Theory, Realiser Functionalism and Machine Functionalism. For present purposes the differences between them are unimportant, but see [31,32] for useful overviews.

${ }^{4}$ For example, the way it feels to be seeing something that is red is a separate mental fact from the fact that it is redness that is perceived. As Nagel puts it, there is something 'it is like' to be in a certain mental state, and this is distinct from what the subject of the mental state is [35].

${ }^{5}$ For example, a wish is for something beyond the wish itself, anger is about something, desire is for something, fear is of something, belief is that something is the case. Paradigmatic physical properties such as mass or charge, by contrast, just are the properties of their objects, they are not directed at or about anything else [36].
} 
from a special theoretical perspective such as psychology or phenomenology.

Non-Reductive Physicalisms represent a set of views according to which mental events are real and are not just kinds of physical goings-on, but are nevertheless comprehensively contingent on physical goings-on ${ }^{6}$. The differences between views of this kind are about what kinds of material arrangements give rise to contingent mental states. Kim has shown that they are logically inconsistent in the following way. A claim that mental events are real entails that they have causal powers, that is, they are sometimes the cause of other events, mental or physical. However, mental events causing physical events are excluded because in this model the physical world is causally closed. But in this model mental events cannot cause mental events either: because mental events supervene on physical events, the only way a mental state can cause a subsequent one is to instantiate its subvenient physical base, which is impossible because the physical world is causally closed. Therefore mental states can not have causal powers. Therefore, the claim that mental events are real (are not physical events and do have causal powers) is inconsistent with the claim that they supervene on physical events [34]. A weaker claim such as that mental events are real but causally inert would be no help, since that would be selfcontradictory ('real' in the relevant sense means having causal powers), and in any case there is empirical support for mental states having causal powers in phenomena such as the placebo effect [37] and biofeedback [38].

It seems increasingly implausible that the subjective phenomena of consciousness could be explained as arising from the objective properties and processes of a wholly material world. As Heil acknowledged:

“...consciousness is deeply mysterious on anyone's view. We have no idea how to accommodate consciousness to the material world, no idea how to explain the phenomenon of consciousness" [33].

Heil has forcefully questioned the adequacy of the established ontological premises:

"... an impasse currently exists in the philosophy of mind. ...Not only is there little agreement over particular answers, but there is little agreement over what the appropriate questions are. One possibility is that we are floundering because we lack an adequate conceptualization of the territory. Without this, our questions remain out of focus; we are in no position to recognize correct answers even if we had them, or to distinguish truths from pretenders.

...in engaging in ontological investigations we are endeavouring to make sense of issues we should otherwise find perplexing. ... My belief is that, if we get the ontology right, these issues will take care of themselves in the following sense: the remaining questions will be largely empirical hence susceptible to techniques we standardly employ in answering empirical questions." [39].

\footnotetext{
${ }^{6}$ The main ones are: Dual-aspect Monism, Epiphenomenalism, Emergentism, Token Identity Theory and Role Functionalism. For present purposes the differences between them are unimportant, but see [31,32] for useful overviews.
}

\section{METHODOLOGY}

The mainstream view on the nature of the mind is a physicalistic one. I have argued above that the kind of anomalous information access involved in psychic ability (psi) appears to be inexplicable in a physicalistic paradigm, and that the physicalistic paradigm is independently put into doubt by its inability to give a viable account of the ordinary features of consciousness. From this conjunction, it appears that in order to make progress with understanding the nature of anomalous access to information, it might be valuable to consider alterative possibilities for the ontological nature of the mind-body relationship, and if a potentially viable one can be identified, to then explore its implications for the possible nature of psi. In the present paper, I will review the alternative ontological options from the perspective of making such progress, select the most promising one, and consider its implications for a theoretical framework from which the nature of psi can then be analysed.

\section{ANALYSIS}

Any ontology underpinning a philosophy of mind must include two fundamental elements: a view about what kinds of stuff exist, and a view about the relationship of the mind to the body. For example, in Physicalism matter is the only kind of stuff that exists, and this entails, as far as the mindbody relationship is concerned, that minds are modes or functions of goings-on in the body.

The main alternatives to Physicalism are:

- Substance Dualism, the view that mind and body are distinct objects each made from a distinct kind of stuff;

- Idealism, the view that mind is primary and physical reality is derivative (this is the opposite of Physicalism);

- Panpsychism, the idea that matter has both physical and mental properties; and

- Neutral Monism, the view that mind and matter are both derivative, and arise from some more fundamental substance;

- Mysterianism, the view that important aspects of how things are is in principle beyond our ability to discover or understand.

Mysterianism represents a group of views according to which deep aspects of the ultimate nature of things (such as consciousness or the mind-body relationship, or psi) are beyond our ability to uncover, for instance because (a) we are not clever enough to understand them [40,41], or (b) reality is ultimately inherently paradoxical [42], or (c) our investigative attempts are being systematically subverted by a "Cosmic Trickster" [43-45], or (d) reality is inaccessible to us because we can only ever analyse our mental impressions, and not that which gives rise to our mental impressions. The last of these views has been very influential in the history of philosophy (Descartes, Hume, Locke, Berkeley and Kant were all influenced by such views), but has in fact been shown to be fallacious. As John Searle very ably and accessibly explains [46 Ch. 10], having conditional mental impressions of 'external reality' does not deny us access to the 
observation of external things; it just distorts how we see them. Since different conditions differentially distort how things appear to us, we can work out what external things are really like. Proposals such as (a) to (c), on the other hand, cannot be defeated by analysis, but only by counterexamples. It may be that we are cognitively closed to the ultimate answers, or that apparent contradictions in our preliminary findings indicate deep truths about ultimate reality rather than just reflecting our present ignorance, but there cannot be arguments in favour of such views. Such defeatist views are not principled, but merely (as William James put it) "devices for making a luxury of intellectual defeat" [47]. There are many examples from the history of science of claims that some or other phenomenon is unknowable, that subsequently turned out to be prematurely pessimistic. Examples include such issues as the composition of the sky [48, p. 43] and the stars [49]. On the principle that, as Patricia Chuchland put it, "our inability to imagine a mechanism is a rather uninteresting psychological fact about us, not an interesting metaphysical fact about the world" [50], I support setting Mysterianism aside as a serious alternative to Physicalism.

Neutral Monism is the view that there is only one kind of ultimate stuff, and that it is neither physical nor mental (hence 'neutral'). This fundamental stuff can be 'configured' so as to instantiate stuffs that have mental, physical or psycho-physical properties. Bilateral mind/body interaction is then possible, it is claimed, because mental stuff and physical stuff have a common base.

This idea that there is some 'unity' that underpins the plurality of experienced actuality has a very ancient lineage. The neutral fundamental substance of the modern Neutral Monist is very reminiscent of the Tao of Lao Tzu, the prakrti of Patanjali, the Brahman of the Upanishads, and the apeiron of the Pre-Socratic philosopher Anaximander.

The modern articulation of Neutral Monism as a philosophical position is due to Bertrand Russell, especially his [51]. In recent times it is an unpopular view, largely because of accusations that Russell's model is faulty, and ends up being (depending on the critic) something close to, if not actually, idealism/panpsychism/phenomenalism [52]. For present purposes, the main problem is that whatever is claimed to arise from the primitive stuff reduces the model, in explanatory terms, to one of the others as far as building theories and answering challenges is concerned, so we should first solve the mind-body relationship in terms of one of the other models, and only then can we investigate whether the stuff of that ontology is fundamental, or derivative from a more fundamental stuff ${ }^{7}$.

Panpsychism is "the view that the basic physical constituents of the universe have mental properties, irrespective of whether they are parts of living organisms" [35]. Panpsychic ideas can be traced back to Pre-Socratic Greek philosopher Anaxagoras (c. 500-425 B.C.), but the modern articula-

\footnotetext{
${ }^{7}$ As Descartes aptly remarked about his own model of dual substances in a letter to Hobbes: "...it is perfectly reasonable...for us to use different names for substances that we recognize as being the subjects of quite different acts or accidents [modes]. And...to leave until later the examination of whether these names signify different things or one and the some thing" [53, my insertion].
}

tion of it as an attempt to explain the mind-body relationship is due to Baruch Spinoza [54]. Key defenders of panpsychic views include Alfred North Whitehead [55], Charles Hartshorne and David Ray Griffin [56].

Panpsychism is a problematic perspective for three main reasons. In its basic form, it ascribes awareness (or at least 'proto-awareness') to very simple entities such as electrons, rocks and telephones [57]. However, there appears to be nothing in such a view that explains, or is needed to explain, any aspect of the behaviour of such simple systems.

Secondly, the consciousness that stands in need of an explanantion is a unity, not an aggragate. My mass just is the sum of the masses of my particles, but my consciousness is something other than the sum of the consciounesses present in my particles. The 'point of view' that exists in my consciouness can not be derived or extrapolated from the putative points of view of my constituents [35].

Thirdly, while panpsychism recognises the distinctness of mental properties from physical properties, it does not explain the apparent interaction between mental and physical events. In fact, it denies mind-body interaction, and then invokes Divine intervention to align mental states and physical conditions, so that panpsychism ultimately amounts to a form of psychophysical parallelism:

"The direct implication of Spinoza's view is that while mental occurrences can determine only other mental occurrences and physical motions can determine only other physical motions, mind and body nonetheless exist in preestablished coordination, since the same divine essence forms the connections within both classes and cannot be selfcontradictory" [58].

To those uncomfortable with invoking God to make the theory work, the correlation between thoughts and brain states then becomes a brute force claim, and panpsychism confers no explanatory advantage over physicalism.

Idealism is the view that there are no physical things, only minds and thoughts that represent the appearance of a physical reality. It was famously elaborated in 1710 by Bishop George Berkeley [59] and summed up by the phrase, esse est percipi (aut percipere) - to exist is to be perceived (or to perceive).

Berkeley rejects that any mind-independent things exist, and since there are then no physical events there is no problem of mind/body interaction. Idealism has been very influential in the history of philosophy; so much so that "...in 1887, almost every philosopher in the English speaking world was an idealist" [60]. Idealism was, however, a problematic view from the start, and the history of idealism (and there have been many many forms of it) is a history of attempts at saving appearances and obfuscating weaknesses (ibid., p. 171). To the early-modern philosophers, who understood there to be deep problems with Cartesian dualism (see below), physicalism was not an acceptable alternative to Cartesian dualism due to deeply ingrained religious beliefs, so idealism had to be the right answer; much as to many in the present mainstream physicalism has to be the right answer, even if we can't see how to make it work. 
The first problem with idealism was that, taken to its logical conclusion, it leads to Solipsism, the view that you are the only mind, and other persons are merely ideas in your mind just as the physical world is. Solipsism is a difficult view to dismiss directly, but philosophers generally oppose it on grounds such as that the world appears to be genuinely intricate and surprising in ways that radically exceed human imaginativeness, or that the conduct of other people is best accounted for under an assumption that they have independent mental processes $[61]^{8}$. Rejecting solipsism and staying with multi-minded idealism, however, raises a significant puzzle: every mind experiences an objective world, but these hallucinations are all synchronised in a special way, so that the world I imagine I see looks exactly like the world you imagine would look if viewed from where you imagine me to be, and so on for every mind in the world. When I hallucinate speaking, you hallucinate hearing what I hallucinate saying. What makes all these hallucinatory goings-on consistent in the absence of an actual reality that grounds these different perspectives? Berkeley's answer was that God's providence arranges it that way, so we are back to Divine intervention (or brute force) to make it all work out.

Different philosophers have tried to find objective mental grounds for this alignment of our subjective mental experiences, without invoking God as such. Immanuel Kant suggested the existence of something unknowable that exists beyond mind and sensations ('Transcendental Idealism'). This idea was developed by Fichte ('Moral Idealism'), Schelling ('Aesthetic Idealism'), and Hegel ('Dialectical Idealism', later called 'Objective Idealism'). They all tried to show that ideas arise not from "a contingent unanimity among private, finite fallible human minds, but [from] a necessary, public, objective, and infinite Mind" [60]. Hegel called this "The Absolute Spirit" or simply "The Absolute", something within which everything (time, space, relations, events, and possibilities) exists or occurs, including personal ideas. However, a claim for the existence of "The Absolute" seems no less ad hoc than the Berkeleian God, and is in many ways a less palatable solution, for it puts us back to solipsism, except that now The Absolute Spirit is the single hallucinating mind.

Idealism went into decline early in the $20^{\text {th }}$ century, not so much because of direct philosophical criticisms but rather because of the growing evidence from geology, biology and astronomy that an inorganic world existed long before any organic forms existed. However, it did finally fall to concerted philosophical critiques, especially those of Bertrand Russell, G. E. Moore and A. C. Ewing, which revealed that idealism involves deep logical confusions, so that ultimately it cannot be made to work. Accessible overviews of the arguments can be found in recent works by David Stove [60] and John Searle [62]. The arguments take several forms, and they are rather technical, but I can give some indication here of how they work.

One way of looking at the problem is this: We learn how to think from our experience of the 'apparently' external world. The meanings that our concepts have, and the ration-

\footnotetext{
${ }^{8}$ Ultimately, as I will argue below, solipsism fails because idealism, from which it is extrapolated, can be shown to be logically incoherent.
}

ality of our thought processes, derive from the consistency and coherence of the experienced world. The consequence is that our sanity is contingent on the existential stability and causal integrity of the experienced world. Now, a claim that the experienced world exists only in our thoughts, amounts to a claim that the experienced world is as we find it because of how we think. But that is circular because we think as we $d o$ because of the way the experienced world is in the first place. So the premise that our thinking is sufficient, in itself, to produce the experience of the world we $d o$ experience, is tautological. The proposed argument from this premise, that nothing can exist except by being thought of, is therefore reduced to a brute claim about the issue at stake, namely, the existence (or not) of a mind-independent world. Idealism, on this analysis, is revealed to be an attempt to derive a necessary truth from a tautology [60]. This phrasing of the argument is directed at subjective idealism, the Berkeleian form in which we are separate minds, but in my view the form of the argument is general. Against solipsism, replace 'we' with 'I' to get the same result. Against Hegelian objective idealism, replace 'we' with 'The Absolute' to get the same result?.

A related way of analysing the problem is given by Searle. He argues that the assumption of the existence of a mind-independent world (in Searle's nomenclature, external reality or ER) is a background condition for the intelligibility of statements for which there is a normal understanding. ER is not a belief that makes those statements meaningful, but a pre-theoretical proposition that is prior to beliefs [62]:

"If I say: "Mt. Everest has snow and ice near the summit and there is no snow on Mt. Everest', [then] what I have said is self-contradictory, because the first clause entails the negation of the second. But if I say: 'Mt. Everest has snow and ice near the summit, and external reality has never existed' what I say is literally puzzling. We do not know how to understand it in the normal way, because the second clause doesn't just contradict the first clause but denies a condition that is taken for granted in the normal understanding of the first. ...The price of the abandonment of realism [about the existence of a mind-external reality] is the abandonment of normal understanding. If someone wishes to abandon normal understanding, he or she owes us an account of what sort of understanding is possible" (ibid p.189, my insertions).

\footnotetext{
${ }^{9}$ Idealism seems to be making something of a modern comeback in largely non-philosophical circles, with Consciousness taking the place of God or The Absolute as the source of everything that exists. It is usually presented as a form of neutral monism in which some kind of cosmic or universal consciousness is the underlying 'essence' from which or in which all individual things arise (e.g. the model of Amit Goswami [63]). However, since the most fundamental stuff is then essentially mental, such a view is really a form of idealism, and hence logically flawed. A similar argument holds for personalized versions of such models, sometimes called "quantumconsciousness" models of reality, in which "observer-effects" are said to "produce" the subsequently experienced external reality by "collapsing" a "wave function" representing "evolving probabilities". The logical difficulty for this view is that by making the mental states of the observer the basis of how physical reality turns out, this model becomes subject to the same criticism as that leveled against idealism - granted modulation of an external reality in this way, only rational minds could then produce a coherent and consistent external reality (as we do have), but this is circular if their rationality (sanity) derives from and depends on the causal consistency of the external world (as it does).
} 
The only major view left is Substance Dualism, the view that mind and body are distinct things made from distinct kinds of stuff. Substance dualism has long been viewed as problematic, and in fact it was the perceived problems with substance dualism that spawned the forays into neutral monism, panpsychism, idealism and physicalism in the first place.

The modern formulation of substance dualism, presented in 1641 by Descartes, is essentially a conflation of two distinct claims, namely that minds are distinct things from bodies (I call this view Structural Dualism) and the view that mind-stuff is different from body-stuff (I call this view Hylic Dualism). Descartes's term Substance Dualism can be interpreted either way, and this lack of clarity has led to much trouble in the ensuing debate. David Griffin is exceptional in being careful about making this important distinction [8].

In Descartes's formulation mental stuff and physical stuff have no properties in common; therefore, since physical stuff has spatial properties he argued that minds were not located anywhere $[53,64,65]$. This view raised serious difficulties both in terms of intelligibility and in terms of scientific concerns. In particular, it was not clear what could be meant by something as existing in a concrete way but not being anywhere, by mental stuff as an "an immaterial substance", how mind and body could interact without having properties in common, and how mind and body could interact without violating fundamental scientific principles such as the conservation of energy.

However, the outlook for dualism is not as poor as many have thought it to be. As the philosopher William Lycan, who is not a dualist, has argued in detail [66], the opposition to dualism is largely a matter of fashion rather than their being strong arguments against it, just as physicalism is more a matter of preference rather than their being strong arguments in favour of it. Cartesian dualism is problematic, but that is not to say that there are no viable Non-Cartesian dualisms.

Lycan and others have pointed out that for dualism to be a coherent view the mind must be conceived as being located in space, contra Descartes. Being somewhere is crucial to the idea that the mind is a concrete individual that can stand in a unique casual relationship to a physical body. If this is conceded, and the existence of immaterial substances can be countenanced, then all the other objections that have been raised against dualism either fall away or are reduced to empirical puzzles rather than metaphysical knock-outs [67-70]. Lycan did not object to the notion of an immaterial substance, but it appears unintelligible to many others, ranging from Hobbes [71] to Antony Flew [72]. However, in my view this objection can also be met. I have recently argued that there are uncontroversial examples in modern physics of immaterial substances, that is, concrete kinds of stuff that are not made of matter but can interact with matter. The quantum vacuum in Quantum Field Theory is a case in point ${ }^{10}$.

\footnotetext{
${ }^{10} \mathrm{I}$ am indebted to Bernard Carr for suggesting this particular example in relation to my general argument about space qualifying as a concrete nonphysical substance in certain theories of physics. Carr's own conception of the non-physical is extensively developed in his recent monograph [73]. Carr's model relates mental phenomena to his conception of a non-physical element in nature, but it does not conceptualise the mind as a distinct struc-
}

The implication is that the concept of an 'immaterial substance' is, after all, neither incoherent nor unscientific [69,70 in prep $]^{11}$. This opens up the prospects for a scientific analysis grounded in such a Non-Cartesian Dualism, and such an ontological framework will form a working hypothesis for this paper. In this ontology, the mind exists as an object distinct from the brain/body, is located somewhere in space ${ }^{12}$, and is made of something that is not matter but can interact with it, so that the mind can interact with the body. Questions about the location, powers, composition and natural history of the mind then become amenable to much deeper investigation by scientific methods than has hitherto been thought possible (or even necessary) ${ }^{13}$. Disciplines such as psychology and consciousnesses studies already analyse, by scientific means, the characteristics of and interplay between emotional states and thought processes. However, the present ontological model raises new classes of empirical question, such as what mental stuff is, and how it can be studied. Such investigation can lead to a fundamental theory of the mental, which would ground empirical models of mental phenomena more objectively than correlation studies do.

I call this ontological model, in which the mind is a distinct structure from the body, and mental stuff a different kind of stuff to physical stuff that is nevertheless analysable by science, and hence a natural stuff, Naturalistic Structural Dualism (NSD).

So far, I have argued that explaining psi is a deep challenge given the mainstream's physicalistic ontology. I then reported that this ontology is looking increasingly suspect in view of its inability to support a viable account of the mindbody relationship. Upon a review of the options, I pointed out naturalistic structural dualism as being, on philosophical grounds, the most viable alternative ontological premise. If this premise finds support in independent empirical evidence, then a good case will exist for thinking of the mind as

ture from the body. For a comparison of his model with mine, see my [70 n.d., in prep].

${ }^{11}$ In unrelated research, scientists have suggested that the quantum vacuum may have direct relevance for understanding the nature of consciousness e.g. [74,75]. My philosophical point neither defends, nor draws on, these models.

${ }^{12}$ A claim that the mind is located in space does not carry an entailment for where in space it is under normal conditions. Lycan pointed out that the bar against two objects occupying the same spatial region counts only for material objects, so there is no principled objection to the objectified mind being thought of as 'in the body' [66], and indeed some philosophers take exactly such a view, e.g. Mark Woodhouse [76] . More exotic solutions have also been proposed, such as that the mind is 'in hyperspace' [77]. The claim of a spatial location of course does not carry a commitment as to how it occupies space - is it field-like [as e.g. suggested by 78] or particle-like, and if the latter is it indivisible (as E. J. Lowe thinks [79]) or composite (as Tertullian thought [80])? Also, there is no implication for whether the substantive mind can continue to exist if the body is destroyed, or depends on the body in some way and would break down if the body disintegrates ((as many have pointed out, e.g. 81-83]. These are complex issues to unpick, but for present purposes a resolution of these interesting concerns is not required.

${ }_{13}$ I take it that minds and psi are natural phenomena, and therefore amenable to study by the methods of rational philosophy and science. Psi is paranormal, in that it appears to conflict deeply with orthodox models, but the paranormal is not supernatural (in the sense of containing causes, objects or entities that are beyond analysis). Likewise mental phenomena may in some sense involve non-physical elements, but I do not think that they are unanalysable (although some philosophers do, e.g. Colin McGinn [40]). 
actually (rather than hypothetically) existing distinctly from the body. And if that is the case, then we would have good reason for thinking of psi as representing a faculty of the mind per se.

There is indeed an emerging body of empirical evidence that is most economically interpreted in terms of a dualistic ontology [84]. The most striking cases come from survivors of cardiac arrest who report continuity of consciousness during their cardiac arrest, and are able to accurately report unusual incidents that occurred during the time in which they were clinically dead.

Cardiac arrest is a physiologically brutal event, and it typically leads within $10-20$ seconds to a state of clinical death, with no heartbeat, no breathing, no detectable electrical activity in the brain, and no brain-stem reflexes $[85,86]$. It is a very serious condition to be in, and only about $10 \%$ of people who suffer a cardiac arrest survive it [87-89]. Without medical intervention, cardiac arrest leads under normal conditions within 5 minutes to the onset of irreversible brain damage [90], and within 10 minutes to actual death $[91,90]^{14}$.

Cardiac arrest cases should be carefully distinguished from other serious cardiac incidents such as heart attack, which involves interruption of the blood supply to the heart, cardiac arrhythmia in which the heart beats in an abnormal way, and heart failure, in which the pumping action of the heart is impaired. Heart attack and cardiac arrhythmia can lead to heart failure, and all these can lead to cardiac arrest, but they do not necessarily do so. Only actual cardiac arrest leads to clinical death.

Surprisingly, about $20 \%$ of the people who survive cardiac arrest report that they were aware during the episode [92-95]. More than a hundred such cases have now been published in the scholarly literature [84].

Consciousness during such an episode is clearly incompatible with the idea that complex mental activity depends on complex physical processes in the brain [96,97]. The only physicalistic recourse would appear to be that the experiences do not occur during the period of cardiac arrest, but represent false memories or hallucinations that occurred some time afterwards, perhaps during the revival stage, and are mistakenly associated with the arrest stage.

There has been a substantial scientific debate about this, and many arguments have been advanced purporting to explain these experiences as misinterpretations of what really happened. For instance, it has been proposed that they are transitional-state hallucinations resulting from lack of oxygen, or too much carbon dioxide, or medically administered drugs, or recovery of repressed memories of prior traumas, or psychological coping mechanisms, and so on. So far, each one of these proposals has met with an effective counterargument as to why they are not applicable in these cases. The situation is a complex one, and after 30 years of debate there is still no conclusive outcome, but at present there appears to be no satisfactory explanation for these experiences

\footnotetext{
${ }^{14}$ The signs of clinical death and actual death are the same; the difference is merely that patients in a state of clinical death can be revived with appropriate medical attention.
}

on physicalistic grounds (see Greyson $[98,99]$ and Holden et $a l$. [100] for an up-to-date review of the main arguments and their weaknesses).

Physicalists broadly have to take the position that a suitable physicalistic explanation must exist, and in time it will be uncovered. However, the prognosis for this is not good. There are at least 30 cases described in the scholarly literature where the patient claims not only to have been conscious during their period of cardiac arrest, but to have viewed the natural world from a perspective outside their body, which makes it possible to compare the accuracy of their reported experience with the events that occurred during that time. In a recent review, Janice Holden found that more than $90 \%$ of such reports contained no errors $[100]^{15}$. The greatest challenge is presented by the dozen of these cases in which the report includes an unusual event that was corroborated by other witnesses as having happened at that time $[102-106]^{16}$. These cases do not amount to conclusive evidence of structural mind-body dualism, but they do present a significant prima facie case supporting it.

A working hypothesis that minds are entities that exist distinctly from bodies raises significant philosophical and scientific questions which, to my mind, ought to be considered in much more detail than has been done by advocates of dualism. Dualists tend to move very quickly from some concessionary non-Cartesian dualism to consideration of the possibility of post-mortem continuity of consciousness, and the possible nature of an afterlife, without pausing to consider the immediate consequences of their model for everyday life. If living human beings are structurally dual, how can we characterise the nature of the mind and its potential? How can we investigate it? Where is the mind? How could we locate it? What is the relationship of the mind to the body? And what is the relationship of mind-stuff to matterstuff? ${ }^{17}$ Following up on all these questions will take more consideration that can be given in the present paper, but clearly a rich seam of philosophical investigation has been opened up.

Returning to our starting comments about the nature of psi, it is now clear that it can indeed reasonably be supposed, as Louisa Rhine and others have suggested we should, that psi represents a faculty of the mind per se.

At this stage it is an open question whether these information-accessing faculties can be modelled in terms of sensory channels, or whether a more exotic approach is re-

\footnotetext{
${ }^{15}$ In contrast to this, Penny Sartori found in a control study that survivors of cardiac arrest who did not report NDEs gave highly inaccurate accounts when asked to guess what the resuscitation procedures were like [101].

${ }^{16}$ To date all these cases come from retrospective studies, but a large scale prospective study led by Dr Sam Parnia of the University of Southampton is now underway in the cardiac units of 18 hospitals. The study was launched at the end of 2008, and will take at least 3 years to complete.

${ }^{17}$ The hypothesis that minds are existents distinct from bodies, and that mind-stuff has properties that matter-stuff does not have, does not entail that mind-stuff and matter-stuff are fundamentally different. There is still the possibility that mind-stuff and matter-stuff (and perhaps other kinds of stuff) arise in some way from a more fundamental stuff. My personal theoretical stance is currently in favour of structural dualism about the mind-body relationship, but about the ontological nature of stuffs I favour a neutral monism that underpins an empirical pluralism. However, resolving this issue is unimportant for the purposes of the present paper.
} 
quired. There are different views on this but, as the physicist Jean Burns has argued, if psi does follow laws then it must be compatible with known physical principles, so there should be points of commonality between the nature of psi and known physical principles [107]. In presently known physics all transfers of information involve some sort of a signal (ibid p.8). There are no present candidates for physical signals to mediate psychic information access, but in a pioneering investigation designed by Edwin May and James Spottiswoode, it was found that performance in a remote viewing $\operatorname{task}^{18}$ correlated with the gradient of the Shannon entropy ${ }^{19}$ of the target images, suggesting that some kind of sensor is involved in anomalous information transfer [108]. For the present, the most reasonable working hypothesis is therefore that anomalous access to information is facilitated by a sensory channel of the mind ${ }^{20,21}$.

These conclusions raise an intriguing new possibility. If minds are things, then there are mental things. If minds have senses that can directly sense physical things and physical phenomena (e.g. as in remote viewing), then it seems overwhelmingly likely that minds would also have senses that can directly sense mental things and mental phenomena. The existence of such perception seems to follow directly from the dualistic model we have come to, and it would be a serious challenge for our hypothesis if such perception does not occur.

Assuming that such perception does occur, what form would it take, and how could we identify it? I propose that something like the following might be the case. If minds and bodies have distinct sensory channels, then there would, under appropriate circumstances, be coming into our consciousness concurrent perceptual inputs coming from these two sensory channels. If, for instance, I encounter another living being (i.e. something consisting of both a body and a mind), then there are both physical and mental things to be observed, and the contents of my consciousness should contain more information than what can be observed by, or inferred from, purely physical observation. We do not normally talk about our perceptual experiences in this way, but something like this might be the case and pass us by because of our easy familiarity with its pervasive occurrence.

What might the mind see, and what might the effect of seeing like this entail? Our physical senses sense the properties of physical things (or at least correlates of physical properties) - weights, shapes, colours, smells and so on. Presumably mental senses would see properties (or correlates of properties) of mental things. What might these be? One pos-

\footnotetext{
${ }^{18}$ Remote viewing is the technical term used in parapsychology for the older and more colloquial term 'clairvoyance'. In these experiments, the remote scene or hidden image to be described is called a 'target'.

${ }^{19}$ Shannon entropy is a measure of the average amount of information in a signal.

${ }^{20}$ Psychic ability of course involves both anomalous access to information (e.g. remote viewing) and having anomalous influence (e.g. psychokinesis). An analogous argument to that given above would suggest that anomalous influence is mediated by a motive channel of the mind per se.

${ }^{21}$ Carr has recently proposed a model in which all experiences result from sensory perception of a hyperspatial structure [73], lending further support to the general idea that the mind has sensory channels. Carr's model is however not a dualistic one, so our conceptions of the nature of the mind are rather different.
}

sibility is that mental systems are the proper bearers of 'axionic' properties such as goodness, compassion or wisdom ${ }^{22}$, and affective properties such as anger, or melancholy, or optimism. Such properties cannot rightly be the properties of physical systems given our dualistic ontology ${ }^{23}$. If such a class of sensory channels does exist, I propose we call such perception axionesis.

Alfred North Whitehead, the founder of Process Philosophy, seemed to be making a claim for a sense very like this in his suggestion that the mind has a faculty called 'prehension' that is more fundamental than sensory perception, and is the means by which we 'see' things such as value, beauty, truth, and various matters of fact such as the existence of a real world, temporal change, etc. In his view, sensory perception comes after prehension - it is prehension that enables us to make sense of sensory data, and it is by prehension that we perceive things such as that our body is in pain [8].

Philosophers from a wide variety of disciplines have argued that when we encounter other beings we are directly aware of more than what is physically present before us, or can be inferred from it. Ludwig Wittgenstein, probably the most influential philosopher of the $20^{\text {th }}$ century, perhaps said it most clearly, and least presumptively. He pointed out that we recognise consciousness and affects directly in another person, without inferring it from physical signs or from comparisons of the person's behaviour with memories of our own feelings when we behaved similarly:

"In general I do not surmise fear in him - I see it. I do not feel that I am deducing the probable existence of something inside from something outside; rather it is as if the human face were in a way translucent and that I was seeing it not in reflected light but rather in its own" [109].

and

"My attitude towards him is an attitude towards a soul. I am not of the opinion that he has a soul" [110, emphasis in original].

and

"Consciousness in the face of another. Look into someone else's face, and see the consciousness in it, and a particular shade of consciousness. You see on it, in it, joy, indifference, interest, excitement, dullness and so on. The light in the face of another. Do you look within yourself, in order to recognize the fury in his face? It is there as clearly as in your own breast" [111, emphasis in original].

and

"We see emotion." -- As opposed to what? -- We do not see facial contortions and make inferences from them (like a doctor framing a diagnosis) to joy, grief, boredom. We describe a face immediately as sad, radiant, bored, even when we are unable to give any other description of the features. --

\footnotetext{
${ }^{22}$ From the Greek axios, meaning "worth", and as used in 'Axiology', the branch of philosophy that studies the nature of value judgments, e.g. assessing moral and aesthetic qualities.

${ }^{23}$ Of course for a Physicalist, it follows from their ontological premises that physical systems can have such properties, and how such properties arise from physicality is then the mystery that needs to be explained.
} 
Grief, one would like to say, is personified in the face" [111 emphasis in original].

Maurice Merleau-Ponty, a leading Phenomenologist, makes essentially the same point:

"I know very little, from inside, of the mime of anger so that a decisive factor is missing for any ... reasoning by analogy... I do not see anger or a threatening attitude as a psychic fact hidden behind the gesture, I read anger in it. The gesture does not make me think of anger, it is anger itself" [112], emphasis in the original).

Edmund Husserl, the founder of Phenomenology, suggested that:

"In the world human beings exert 'spiritual influences' upon each other, they enter into contact on the spiritual plane, they act upon each other, I to I; the fact that I do this is known to the other and that determines him to 'orient' himself accordingly from his side" [113].

David Griffin, a prominent Panpsychist and co-founder of The Centre for Process Studies, directly invokes psychic abilities in explaining transpersonal awareness:

“...when we watch and listen to a speaker, we are also receiving, at the same time, telepathic and clairvoyant impressions from her or him. Most of us, most of the time, however, are conscious only of the visual and auditory impressions. This position is a variant of the position taken by Henri Bergson, F. Schiller, and William James" [8].

These quotes from Husserl and Griffin include presumptions about how this might work, but for the present I will put their explanations aside. The important point is that they were aware of the phenomenon, and thought that it stood in need of a special explanation ${ }^{24}$.

This perception is also evident in encounters with nonhuman living beings. Thomas Nagel, a leading philosopher of mind, and author of the justly-famous anti-reductionist paper What is it Like to be a Bat? remarked in a discussion of the inadequacy of physicalistic explanation:

"When a mouse is frightened it does not seem to me that a small material object is frightened" [35].

Being frightened, or fearful, or angry, or loving, is a property of something, but it seems deeply problematic to conceive of it as a property of a purely physical object. And yet it is present, and we do see $\mathrm{it}^{25}$.

\footnotetext{
${ }^{24}$ Wittgenstein, Merleau-Ponty and Husserl strongly defended the idea that human beings are behaviourally and experientially psycho-somatic units, without making metaphysical commitments about the nature of the mind. Such pragmatic perspectives are neutral with respect to structural dualism. Descartes himself insisted on (and was baffled by) psycho-somatic unity, declaring: “...I am not merely present in my body as a sailor is present in his ship, but I am very closely joined, and, as it were, intermingled with it, so that I and the body form a unit. If this were not so, I...would not feel pain when the body was hurt, but would perceive the damage purely by the intellect, just as a sailor perceives by sight if anything in his ship is broken" [53].

${ }^{25}$ Phenomenologists such as Husserl and Merleau-Ponty, whose observations I have quoted above, make a distinction between the physical body as an object (körper, in German) and the physical body as a living thing, the 'lived body' (leib, in German). In phenomenology the leib is a 'physical body' that indeed can be fearful, angry or loving. However, the phenome-
}

The direct perception of such states is so natural to us that we are not usually aware that such perception is involved. Its existence becomes powerfully evident, though, in cases where people apparently have impaired perception of this kind, such as in autism. In this revealing excerpt Oliver Sacks describes his encounter with the now well-known autist Temple Grandin:

"I was struck by the enormous difference, the gulf, between Temple's immediate, intuitive recognition of animal moods and signs and her extraordinary difficulties understanding human beings, their codes and signals, the way they conduct themselves. One cannot say that she is devoid of feeling or has a fundamental lack of sympathy. On the contrary, her sense of animals' moods and feelings is so strong that these almost take possession of her, overwhelm her at times. She feels she can have sympathy for what is physical or physiological - for an animal's pain or terror - but lacks empathy for people's states of mind and perspectives. When she was younger, she was hardly able to interpret even the simplest expressions of emotion; she learned to 'decode' them later... Temple had longed for friends at school and would have been totally, fiercely loyal to a friend..., but there was something about the way she talked, the way she acted, that seemed to alienate others... Something was going on between the other kids, something swift, subtle, constantly changing - an exchange of meanings, a negotiation, a swiftness of understanding so remarkable that sometimes she wondered if they were all telepathic. She is now aware of the existence of these social signals. She can infer them, she says, but she herself cannot perceive them, cannot participate in this magical communication directly..." [114].

Clearly people can be, as Wittgenstein put it, 'aspect blind'. I propose that in instances such as these it is due to a drastic attenuation in some channels of their mental sensory perception (axionesis). Instances such as these expose how very real, and important, axionesis is in normal life. In a dualistic ontology, it could therefore be proposed that abilities such as what is ordinarily called 'perceptiveness' are in fact contingent on special sensory perceptions that operate directly between mental systems without physical intermediaries.

In my view these quotes indicate that in ordinary interpersonal engagements there is more information in a person's consciousness than can be derived from their physical perception. However, the processing power of the brain is vast, and one could argue on such grounds that these perceptions are just inferences from physical cues after all. In the examples just given, there was always a physical information stream present alongside the suggested mental information stream, so this suspicion has some force. However, if the mind really has sensory channels that can directly sense mental states of affairs, then they must presumably be able to do this even when such correlating physical clues are absent.

nological perspective does not entail an ontology - it does not specify in virtue of what the leib is a physical thing and yet not a körper. The phenomenological approach is useful for pointing up mental properties exactly because it approaches experience completely open-mindedly, without an ontological bias about substances. However, it leaves open the specific issue that is the subject of this paper, namely what sense we are to make, ultimately and fundamentally, of our experiencing of mental properties. 
If such perception does not appear to exist it would considerably weaken the case for the existence of axionesis.

In my view such perception does exist, and one particular example of it has been convincingly identified in scientific studies. It is called 'the staring effect', and relates to the widespread anecdotal experience of being able to tell when someone is staring at you even if you are not looking at them at the time. It has been the subject of substantial research in recent times. In surveys, around $75 \%$ of men, and $80 \%$ of women, claim to have experienced this [115]. In controlled experimental studies the effect has been shown to be real with very high statistical significance $\left(\mathrm{p}<1 \times 10^{-25}\right)$ [116]. The leading researcher in this area is Rupert Sheldrake [10,116-119], but the effect has been studied experimentally for over a century. See Sheldrake [115] for an accessible overview of research into this phenomenon.

"Most people take these experiences for granted and pay little attention to them. But some people observe others for a living. The sense of being stared at is well known to many police officers, surveillance personnel and soldiers, as I have found through an extensive series of interviews. Most were convinced of the reality of this sense, and told stories about times when people they were watching seemed to know they were being observed, however well the observers were hidden. When detectives are trained to follow people, they are told not to stare at their backs any more than necessary, because otherwise the person might turn around, catch their eye and blow their cover. ... Several celebrity photographers and army snipers told me that they were convinced that some people could tell when they were being looked at through telephoto lenses or telescopic sights. In some of the oriental martial arts, students are trained to increase their sensitivity to being looked at from behind. Many species of non-human animals also seem able to detect looks. Some pet owners claim that they can wake their sleeping dogs or cats by staring at them. Some hunters and wildlife photographers are convinced that animals can detect their gaze even when they are hidden and looking at animals through telescopic lenses or sights. Conversely, some photographers and hunters say they have felt when they were being looked at by wild animals" (ibid p. 11).

Such cases provide strong support for the argument that a category of purely mental sensory channels does exist, and that everyday 'perceptiveness' is mediated by axionesis.

A much more prominent effect of this kind occurs during certain so-called 'spiritual experiences', in which people appear to engage with a 'transcendental' reality, sometimes including 'spiritual' entities. In the argument to follow, I will argue firstly that we have some cause to grant these experiences a measure of objective reality, and then contend that in these experiences people sometimes perceive axionic properties in a very vivid way.

About half of the people who report consciousness during a cardiac arrest relate such transcendental experiences. These cardiac arrest experiences are a subset of a class of experiences known as near-death experiences (NDEs). These occur in a wide variety of contexts such as birth trauma, surgical emergency, accidents, suicide attempts etc. They are qualitatively indistinguishable $[4,98,120-122]$ allowing us (at least provisionally) to view all NDEs as broadly representing the same kind of disruption to system functioning. The idea that such visions at least to some degree reflect an objective reality is significantly reinforced by the consistency with which certain thematic elements occur in these experiences across a wide variety of cultures [123] going back to very ancient times [124]. Even more significantly, in some of these transcendental experiences people obtain veridical information about remote events or distant family members [4,14,101,125-127]. Given such consistent and veridical elements, these experiences can not be wholly subjective phenomena such as hallucinations. Importantly for present purposes, in the cardiac arrest cases the physical sensory system is shut down, so it seems that whatever is perceived in these spiritual experiences is mediated purely by mental sensory channels. A very common report from such cases is that people meet spirit beings, often described as 'radiant' or even 'a being of light'. The point of special interest for the present investigation is that people often report strong direct perception of axionic qualities in these situations, for instance:

"...I floated...up into this pure crystal light...it was beautiful, and so bright, so radiant, but it didn't hurt my eyes. It's not any kind of light you can describe on earth. I didn't actually see a person in this light, and yet it has a special identity, it definitely does. It is a light of perfect understanding and perfect love" [128].

"I recall thinking to myself 'This is it - Death.' And 'looked around' to see straight ahead a bright light, sending warmth and benevolence..." [129].

"All the time I was up there I never felt afraid, or alone. There was someone or something up there. A presence that radiated love, joy, warmth and deep awesome spiritual feeling... It was the most beautiful experience I have ever had, and I will always cherish it" [120].

"Around me, as the tunnel began to lighten, there were presences. They were not people, and I didn't see anything, but I was aware of their minds...There was total wisdom and goodness in them" [4] (emphasis in original).

These cases suggest that the perception that mediates access to information about spiritual qualities during transcendental experiences is a strong form of axionesis. The implication is that the capacity whereby people gain information with significant spiritual meaning during transcendental experiences ('spiritual awareness') rests on the same ability that enables people to gain information about mental phenomena in ordinary experience ('perceptiveness').

\section{DISCUSSION AND CONCLUSIONS}

I have argued that explaining psi is a deep challenge given the mainstream physicalistic ontology, and reported that this ontology is looking increasingly suspect in view of its inability to support a viable account of the mind-body relationship. Upon a review of the options, I pointed out structural dualism as being, on philosophical grounds, the most viable alternative ontological premise. I then presented empirical evidence of continuity of consciousness during cardiac arrest, which provides strong support for the idea that minds are in fact concrete existents distinctly from bodies. 
I have argued that given such a model, anomalous access to information is most economically interpreted as mediated by sensory channels of the mind, and showed that these come in two classes. The first of these can directly perceive the presence and properties of physical objects and phenomena, and this corresponds to what has classically been called 'psychic perception'. The second of these can directly perceive the presence and properties of mental entities, and this corresponds to what has classically been called 'spiritual awareness'. I have argued that spiritual awareness is an intense form of what is ordinarily called 'perceptiveness', and named this kind of perception 'axionesis'.

Anomalous access to information about the physical world (psychic perception) has a counterpart in an anomalous ability to influence the physical world (psychokinesis), which we can now likewise argue is a motive channel of the mind. Abilities and behaviours mediated by the combination of these mental channels that engage with the physical world represent what is broadly called 'psychic ability'.

Anomalous access to information about the mental (or transcendental) world (spiritual awareness) has a counterpart in an anomalous ability to directly affect mental states, what we may call 'spiritual agency'. For instance, people report being affected by encounters with seasoned meditation practitioners [130] or by just being in the presence of "naturally good' people like the Dalai Lama. The psychologist and expert researcher into emotions Paul Ekman, in a meeting with the Dalai Lama, experienced a spontaneous remission of his quickness to anger that he had struggled with for more than forty-five years:

"I had a very strong physical sensation for which we do not have an English word - it comes closest to "warmth", but there was no heat. It certainly felt very good, and like nothing I have felt before or after... As a scientist, I cannot ignore what I experienced... I think the change that occurred within me started with that physical sensation. I think that what I experienced was - a non-scientific term - "goodness". Every one of the other eight people [who reported similar experiences] I interviewed said they felt goodness; they felt it radiating and felt the same kind of warmth that I did. I have no idea what it is or how it happens, but it is not my imagination. Though we do not have the tools to understand it, that does not mean it does not exist" [131, my insertion].

Encounters with the 'being of light' during NDEs similarly appear to have a lasting positive effect on people more than $80 \%$ of NDErs report a strong positive change in their attitudes [99,132-134], and Melvin Morse has found that "the deeper the experience of light, the greater the transformation" [135]. These effects could be interpreted as representing a mental motive channel. Abilities and behaviours mediated by the combination of these sensory and motive mental channels that engage with the mental world could then represent what is broadly called 'spirituality'.

The term 'psi' has been coined to represent the ability to access information, or exert influence, in ways not mediated by the physical body's known faculties. I have argued that we can view psi as mediated by the faculties of a distinctly existing mind. Traditionally, the term psi has been regarded as a replacement for the older term 'psychic ability ${ }^{26}$. The present analysis expands the concept of psi to include two distinct classes of psi, corresponding to the classical notions of psychic ability and spirituality.

By investigating the anomalous access to information in psychic ability, we have opened up a window on the nature of spirituality. Obviously much more work is required to fully understand spirituality, but by exposing its relationship to a sensory channel of the mind, a framework now exists to study spirituality in terms of information theory.

"Someday after we have mastered the winds, the waves, the tides, and gravity, we shall harness....the energies of love. And on that day, for the second time in the history of the world, man will have discovered fire." Teilhard de Chardin [137].

\section{ACKNOWLEDGEMENTS}

Aspects of this research were presented at the 2009 conferences of the Society for Psychical Research and the Transpersonal Psychology Section of the British Psychological Society, and I am indebted to these audiences for challenging questions and helpful comments. I would like to particularly thank Michael Potts, Julie Rousseau, Zofia Weaver, Bruce Greyson, David Luke, Andrew Powell, and Gregory Shushan for stimulating discussions on aspects of this research, which greatly improved the end result, and to absolve them of any responsibility for weaknesses in the final product. I would also like to thank the three anonymous reviewers for their insightful comments and helpful suggestions. I am grateful to the Society for Psychical Research for their financial support and encouragement with this research project.

\section{REFERENCES}

[1] Sidgwick H, Johnson A, Myers FWH, Podmore F, Sidgwick EM Report on the Census of Hallucinations. Proc Soc Psychical Res 1894; 10: 25-422.

[2] Gurney E, Myers FWH, Podmore F. Phantasms of the living. London: The Society for Psychical Research; Trübner and Co.; 1886.

[3] Luke D. Psychedelic substances and paranormal phenomena: a review of the research. J Parapsychol 2008; 72: 77-107.

[4] Fenwick P, Fenwick E. The truth in the light : an investigation of over 300 near-death experiences. London: Headline; 1995.

[5] Patanjali. Patanjali's Yoga Sutra. London: Penguin Classics; 2009.

[6] James W. The varieties of religious experience: a study in human nature, being the Gifford lectures on natural religion delivered at Edinburgh in 1901-1902, by William James. London: Longmans Green; 1902.

[7] Marshall P. Mystical encounters with the natural world: experiences and explanations. Oxford: Oxford University Press 2005.

[8] Griffin D. Parapsychology, philosophy, and spirituality : a postmodern exploration. Albany: State University of New York Press 1997.

[9] Radin D. The conscious universe : the scientific truth of psychic phenomena. 1st ed. New York N.Y.: HarperEdge; 1997.

[10] Sheldrake R. The sense of being stared at : And other aspects of the extended mind. 1st ed. New York: Crown Publishers; 2003.

[11] Palmer J. A community mail survey of psychic experiences. J Am Soc Psychical Res 1979; 73(3): 221-251.

[12] Thalbourne MA. The SPR centenary census: II. The survey of beliefs and experiences. J Soc Psychical Res 1994; 59: 420-31.

\footnotetext{
${ }^{26}$ In fact, the term 'psi' was introduced in order to have a more ontologically neutral term in the absence of any real ideas about how psi works [136].
} 
[13] Thalbourne M. A note on paranormal belief and paranormal experience: their levels, absolute and relative. J Soc Psychical Res 2004; 68.2(875): 115-21.

[14] Cardeña E, Lynn SJ, Krippner S, Eds. Varieties of anomalous experience : examining the scientific evidence. Washington DC: American Psychological Association; 2000.

[15] Haraldsson E. Representative national surveys of psychic phenomena: Iceland, Great Britain, Sweden, USA, and Gallup's multinational survey. J Soc Psychical Res 1985; 53: 145-58.

[16] Irwin HJ, Watt C. An introduction to parapsychology. McFarland \& Co Inc Pub; 2007.

[17] Storm L, Thalbourne MA. The effect of a change in pro attitude on paranormal performance: A pilot study using naïve and sophisticated skeptics. J Sci Explor 2005; 19(1): 11-29.

[18] Shiah Y. Can ESP be trained? A model for ESP training. J Soc Psychical Res 2009; 73.4(897): 231-43.

[19] Kari J. Informational uses of spiritual information: an analysis of messages reportedly transmitted by extraphysical means. J Inf Sci 2009; 35(4): 453-68.

[20] Parapsychological Association. Glossary of Psi (Parapsychological) Terms (L-R) [Internet]. [cited 2009 Oct 23]; Available from: http: //parapsych.org/glossary_l_r.html\#p

[21] Rhine L. Hidden channels of the mind. New York: W. Sloane Associates; 1961

[22] Chalmers D. Facing up to the problem of consciousness. J Conscious Stud 1995; 2(3): 200-219.

[23] Taylor CCW. Pleasure, mind, and soul: selected papers in ancient philosophy. Oxford: Oxford University Press 2008.

[24] Feyerabend P. Materialism and the Mind-Body Problem. Rev Metaphys 1963; 17(1): 49-66.

[25] Dennett D. Consciousness explained. 1st ed. Boston: Little Brown and Co.; 1991.

[26] Dennett D. What RoboMary knows. In: Sweet dreams : philosophical obstacles to a science of consciousness. Cambridge Mass.: MIT Press; 2005.

[27] Jackson F. Epiphenomenal Qualia. Philos Q 1982; 32(127): 12736

[28] Jackson F. What mary didn't know. J Philos 1986; 83(5): 291-5.

[29] Beaton M. What RoboDennett still doesn't know. J Conscious Stud 2005; 12: 3-25.

[30] Smythies J. Brain and consciousness: The ghost in the machines. J Sci Explor 2009; 23(1): 37-58.

[31] Rose D. Consciousness : philosophical, psychological and neural theories. Oxford: Oxford University Press; 2006.

[32] Velmans M, Schneider S. The Blackwell companion to consciousness. Oxford: Blackwell Pub.; 2007.

[33] Heil J. Philosophy of mind : a contemporary introduction. 2nd ed. New York: Routledge; 2004.

[34] Kim J. Philosophy of mind. 2nd ed. Boulder Colo.: Westview Press; 2006.

[35] Nagel T. Mortal questions. Cambridge: Cambridge University Press; 1979.

[36] Brentano F. Psychology from an empirical standpoint. London: Routledge and Kegan Paul; 1874.

[37] Benedetti F, Mayberg HS, Wager TD, Stohler CS, Zubieta J. Neurobiological mechanisms of the placebo effect. J Neurosci 2005; 25(45): 10390-402.

[38] Basmajian JV. Control of individual motor units. Am J Phys Med 1967; 7: 299-316

[39] Heil J. From an ontological point of view. Oxford: Oxford University Press; 2003.

[40] McGinn C. Problems in philosophy: The limits of inquiry. Philos Q 1996; 46(182): 117.

[41] McGinn C. The mysterious flame : conscious minds in a material world. New York: Basic Books; 1999.

[42] Anderson J. In defence of mystery: a reply to Dale Tuggy. Religious Stud 2005; 41(02): 145-63

[43] Kennedy JE. The capricious, actively evasive, unsustainable nature of psi: A summary and hypotheses. J Parapsychol 2003; 67(1): 5375 .

[44] Beloff J. Lessons of history. J Am Soc Psychical Res 1994; 88: 722.

[45] Hansen G. The trickster and the paranormal. Philadelphia PA: Xlibris Corp.; 2001

[46] Searle JR. Mind: A Brief Introduction. Oxford: Oxford University Press; 2005.
[47] James W. The principles of psychology : in two volumes [Vol 1] New York: Henry Holt \& Co.; 1890.

[48] Collinson D, Plant K, Wilkinson R. Fifty Eastern Thinkers. Routledge; 2000.

[49] Comte A. Cours de philosophie positive. Paris: Borrani et Droz 1852.

[50] Churchland PS. The hornswoggle problem. J Conscious Stud 1996; 3(5-6): 402-8.

[51] Russell B. The analysis of mind. London: G. Allen \& Unwin Ltd.; 1921.

[52] Stubenberg L. Neutral Monism [Internet]. In: Zalta EN, Ed. Stanford Encyclopedia of Philosophy. (Fall 2008 ed.). 2008 [cited 2009 Oct 28]; Available from: http://plato.stanford.edu/archives/ fall2008/entries/neutral-monism/

[53] Descartes R, Cottingham J, Stoothoff R, Murdoch D. The philosophical writings of Descartes. Cambridge: Cambridge University Press; 1985; Vol. 2 of 3.

[54] Spinoza B. De Ethica. In: Opera posthuma. Amsterdam Macerata: Quodlibet 2008; 1677

[55] Whitehead A. Process and Reality: an essay in cosmology. Cambridge: Cambridge University Press; 1929.

[56] Griffin D. Unsnarling the world-knot consciousness, freedom, and the mind-body problem. Berkeley CA: University of California Press; 1998.

[57] Popper K, Eccles J. The self and its brain. New York: Springer International; 1977.

[58] Wozniak RH. Mind And Body: René Descartes To William James [Internet]. 1992. Available from: http: //serendip.brynmawr.edu/exhibitions/Mind/17th.html [cited 2009 Oct 6].

[59] Berkeley G. A treatise concerning the principles of human knowledge. Indianapolis: Hackett Pub. Co. 1995; 1710.

[60] Stove D. The Plato cult and other philosophical follies. Oxford: Blackwell; 1991.

[61] Hyslop A. Other Minds [Internet]. In: Zalta, EN, Ed. Stanford Encyclopedia of Philosophy. (Fall 2008 ed.). 2008 [cited 2009 Nov 2]; Available from: http://plato.stanford.edu/archives/fall2008/ entries/other-minds/

[62] Searle J. The construction of social reality. London: Allen Lane; 1995.

[63] Goswami A. The hard questions: View from a science within consciousness. [Internet]. 1996 [cited 2010 Mar 16]: Available from: http://members.aol.com/NeoNoetics/Goswami HardProblem.html

[64] Descartes R, Cottingham J, Stoothoff R, Murdoch D. The philosophical writings of Descartes. Cambridge: Cambridge University Press 1985; Vol. 1

[65] Descartes R, Cottingham J, Stoothoff R, Murdoch D, Kenny A The philosophical writings of Descartes. Cambridge: Cambridge University Press; 1991; Vol. 3.

[66] Lycan WG. Giving dualism its due. Australas J Philos 2009; 87(4): 551-63.

[67] Dilley FB. Taking consciousness seriously: A defense of Cartesian dualism. Int J Philos Religion. 2004; 55(3): 135-53.

[68] Flew A. Is there a case for bodied survival? In: Flew A, Eds. Readings in the philosophical problems of parapsychology. Buffalo N.Y.: Prometheus Books; 1987. p. 347-61.

[69] Rousseau D. Beyond the irreducible mind: Evidence is not enough. Presented at the 33rd International Conference of the Society for Psychical Research, 4-6 Sept 2009. University of Nottingham: SPR 2009.

[70] Rousseau D. If minds are not just brains, what might they be? Presentation to the Scientific and Medical Network, 18 November 2009, Guildford: SMN 2009.

[71] Hobbes T. Leviathan. (first publication 1651). Cambridge: University Press 1904.

[72] Flew A. The presumption of atheism, and other philosophical essays on God, freedom and immortality. London: Elek/Pemberton 1976.

[73] Carr B. Worlds Apart? Can Psychical Research Bridge the Gulf between Matter and Mind? Proc Soc Psychical Res 2008; 59(221): $1-96$.

[74] Hameroff S. Whitehead and quantum computation in the brain: panprotopsychism meets the physics of fundamental spacetime geometry. In: Weber M, Ed. Whitehead Process Network Compendium. 2003. 
[75] Laszlo E. Science and the Akashic field : an integral theory of everything. Rochester Vt.: Inner Traditions; 2004.

[76] Woodhouse MB. Paradigm Wars: Worldviews for a New Age. Berkeley CA: Frog Ltd; 1996.

[77] Audain L. Near-Death Experiences and the Theory of the Extraneuronal Hyperspace. J Near-Death Stud 1999; 18(2): 103-15.

[78] Mays RG, Mays SB. The phenomenology of the self-conscious mind. J Near-Death Stud 2008; 27(1): 5-45.

[79] Lowe EJ. Subjects of Experience. Cambridge: Cambridge University Press; 2006.

[80] Potts M, Devanno A. Can Tertullian's Theory of the Soul Offer Anything Useful for Parapsychology? Presented at the 33rd International Conference of the Society for Psychical Research, 4-6 Sept 2009. University of Nottingham: 2009.

[81] Ducasse C. A critical examination of the belief in a life after death. Springfield Ill.: Charles C. Thomas; 1961.

[82] Irwin H. Flight of mind : a psychological study of the out-of-body experience. Metuchen N.J.: Scarecrow Press; 1985.

[83] Woodhouse MB. Out-of-body experiences and the mind-body problem. New Ideas Psychol 1994; 12(1): 1-16.

[84] Kelly E, Kelly E, Crabtree A, Gauld A, Grosso M, Greyson B. Irreducible mind : toward a psychology for the 21 st century. Lanham Md.: Rowman \& Littlefield; 2007.

[85] Fenwick P, Fenwick E. The Art of Dying. London: Continuum; 2008.

[86] Greyson B. Implications of near-death experiences for a postmaterialist psychology. Psychol Religion Spiritual 2010; in press.

[87] Peberdy MA, Ornato JP, Larkin GL, et al. Survival From InHospital Cardiac Arrest During Nights and Weekends. JAMA 2008; 299(7): 785-792.

[88] Nichol G, Thomas E, Callaway CW, et al. Regional variation in out-of-hospital cardiac arrest incidence and outcome. JAMA 2008; 300(12): 1423-31.

[89] Ballew KA. Recent advances: Cardiopulmonary resuscitation. BMJ 1997; 314(7092): 1462

[90] Safar P. Resuscitation from clinical death: Pathophysiologic limits and therapeutic potentials. Crit Care Med 1988; 16(10): 932-41.

[91] Kaplan JL. Cardiac Arrest: First Aid: Merck Manual Home Edition 2007. Available from: http: //www.merck.com/mmhe/sec24/ch299/ ch299c.html [cited 2009 Aug 14].

[92] Greyson B. Incidence and correlates of near-death experiences in a cardiac care unit. Gen Hosp Psychiatry 2003; 25(4): 269-76.

[93] Parnia S, Waller DG, Yeates R, Fenwick P. A qualitative and quantitative study of the incidence, features and aetiology of near death experiences in cardiac arrest survivors. Resuscitation 2001; 48(2): $149-56$.

[94] Van Lommel P, Van Wees R, Meyers V, Elfferich I. Near-death experience in survivors of cardiac arrest: a prospective study in the Netherlands. Lancet 2001 12; 358(9298): 2039-45.

[95] Schwaninger J, Eisenberg PR, Schechtman KB, Weiss AN. A prospective analysis of near-death experiences in cardiac arrest patients. J Near-Death Stud 2002; 20(4): 215-32.

[96] Greyson B. Biological aspects of near-death experiences. Perspect Biol Med 1998; 42(1): 14-32.

[97] Parnia S, Fenwick P. Near death experiences in cardiac arrest: visions of a dying brain or visions of a new science of consciousness. Resuscitation 2002; 52(1): 5-11.

[98] Greyson B. Near-death experience: clinical implications. Rev Psiquiatr Clín 2007; 34 (suppl. 1): 116-25.

[99] Greyson B. Near-Death Experiences and Spirituality. Zygon 2006; 41(2): 393-414.

[100] Holden JM, Greyson B, James D, Eds. The Handbook of Neardeath Experiences: Thirty Years of Investigation. Oxford: Praeger; 2009.

[101] Sartori P. The near-death experiences of hospitalized intensive care patients: A five-year clinical study. Lampeter: Edwin Mellen Press Ltd; 2008

[102] Sharp K. After the light : what I discovered on the other side of life that can change your world. 1st ed. New York: William Morrow and Co.; 1995.

[103] Cook EW, Greyson B, Stevenson I. Do any near-death experiences provide evidence for the survival of human personality after death?
Relevant features and illustrative case reports. J Sci Explor 1998; 12(3): 337-406.

[104] Ring K, Cooper S. Mindsight : near-death and out-of-body experiences in the blind. 1st ed. Palo Alto Calif.: William James Center for Consciousness Studies; 1999.

[105] Ring K, Lawrence M. Further evidence for veridical perception during near-death experiences. J Near-Death Stud 1993; 11(4): 223-9.

[106] Moody R. The light beyond. Toronto: Bantam Books; 1988.

[107] Burns J. What is beyond the edge of the known world? J Conscious Stud 2003; 10: 7-28.

[108] May E, Hyslop J, Faith L. The correlation of the gradient of shannon entropy and anomalous cognition: Toward an AC Sensory System. J Sci Explor 2000; 14(1): 53-72.

[109] Wittgenstein L. Remarks on the philosophy of psychology. Chicago: University of Chicago Press; 1988.

[110] Wittgenstein L. Philosophical Investigations: The german text, with a revised english translation. Oxford: WileyBlackwell; 2001.

[111] Wittgenstein L. Zettel. Berkeley CA: University of California Press 2007; 1967.

[112] Merleau-Ponty M. Phenomenology of perception. New York: Humanities Press; 1962.

[113] Husserl E. Zur Phaänomenologie der Intersubjektivitaät. Den Haag Martinus Nijhoff 1973.

[114] Sacks OW. An anthropologist on Mars. New York: Vintage Books; 1995.

[115] Sheldrake R. The sense of being stared At -- Part 1: Is it real or illusory? J Conscious Stud 2005; 12: 10-31.

[116] Sheldrake R. The sense of being stared at confirmed by simple experiments. Biol Forum 1999; 92: 53-76

[117] Sheldrake R. The "Sense of being stared at" Does not depend on known sensory clues. Biol Forum 2000; 93: 209-24.

[118] Sheldrake R. The sense of being stared At -- Part 2: Its implications for theories of vision. J Conscious Stud 2005; 12: 32-49.

[119] Sheldrake R. The non-visual detection of staring -- response to commentators. J Conscious Stud 2005; 12: 117-26.

[120] Fox M. Religion, spirituality, and the near-death experience. London: Routledge; 2003.

[121] Greyson B. Near-death experiences precipitated by suicide attempt Lack of influence of psychopathology, religion, and expectations. J Near-Death Stud 1991; 9(3): 183-188.

[122] Greyson B, Stevenson I. The phenomenology of near-death experiences. Am J Psychiatry 1980; 137: 1193-6.

[123] Greyson B. Near-Death Experiences. In: Cardeña E, Lynn SJ, Krippner S, Eds. Varieties of anomalous experience : examining the scientific evidence. Washington DC: American Psychological Association; 2000

[124] Shushan G. Conceptions of the afterlife in early civilizations universalism, constructivism, and near-death experience. London; Continuum; 2009.

[125] Badham P, Badham L. Immortality or extinction? 2nd ed. London: SPCK; 1984

[126] Greyson B. Seeing dead people not known to have died: "Peak in Darien" Experiences. Anthropol Hum 2010; in press.

[127] Schwaninger J, Eisenberg PR, Schechtman KB, Weiss AN. A Prospective analysis of near-death experiences in cardiac arrest patients. J Near-Death Stud 2002; 20(4): 215-32.

[128] Moody R. Life after life : the investigation of a phenomenon-survival of bodily death. St. Simons Island GA: Mockingbird Books; 1975

[129] Fox M. Spiritual encounters with unusual light phenomena : lightforms. Cardiff: University of Wales Press; 2008.

[130] Goleman D. Emotional intelligence. New York: Bantam Books; 2005.

[131] Ekman P, Ed. Emotional awareness. New York: Henry Holt; 2008.

[132] Bauer M. Near-death experiences and attitude change. Anabiosis JNear- Death Stud 1985; 5(1): 39-47.

[133] Ring K, Valarino EE. Lessons from the light: what we can learn from the near-death experience. New York: Insight Books; 1998.

[134] Musgrave C. The near-death experience: A study of spiritual transformation. J Near-Death Stud 1997; 15: 187-201.

[135] Morse M, Perry P. Transformed by the light : the powerful effect of near-death experiences on people's lives. London: Piatkus; 1993. 
[136] Thouless RH, Wiesner BP. The Psi processes in normal and "Paranormal" psychology. Proc Soc Psychical Res 1948; 48(174): 17796.
[137]

Chardin PTD. Toward the future. New York: Harcourt Brace Jovanovich; 1975.

Received: March 30, 2010

(C) David Rousseau; Licensee Bentham Open.

This is an open access article licensed under the terms of the Creative Commons Attribution Non-Commercial License (http://creativecommons.org/ licenses/by-nc/3.0/) which permits unrestricted, non-commercial use, distribution and reproduction in any medium, provided the work is properly cited. 